\title{
Review to Daniel Hutto and Erik Myin's Evolving Enactivism: Basic Minds Meet Content. MIT Press, 2017.
}

\author{
Resenha ao Evolving Enactivism: Basic Minds \\ Meet Content. Massachusetts: MIT Press, 2017 \\ de Daniel Hutto e Erik Myin.
}

Marcos Silva

Professor do departamento de filosofia da UFPE

Carlos Brito

Professor de ciência da computação da UFC

Francicleber Ferreira

Professor de ciência da computação da UFC

\begin{abstract}
In this review, Hutto and Myin's new book "Evolving Enactivism: Basic Minds Meet Content" (2017) is critically presented. Although they do not provide a detailed cognitive science theory based on their Radical Enactive approach, one may say that Hutto and Myin originally address the perennial philosophical issue about our nature as human beings giving an impossible-to-neglect enactivist contribution to the current state-of-art in the discussion concerning embodied cognition.
\end{abstract}

Keywords: Embodied Cognition, Philosophy of Cognitive Sciences, Philosophy of Mind, Enactivism, Representationalism. 
Resumo: Nesta resenha, o novo livro "Evolving Enactivism: Basic Minds Meet Content" de Daniel Hutto e Erik Myin (2017) é apresentado e criticado. Apesar de seus autores não oferecerem uma teoria cognitiva detalhada baseada em sua abordagem enativa radical, pode-se afirmar que Hutto e Myin tratam de maneira original o problema filosófico perene sobre a nossa natureza como seres humanos, ao darem uma contribuição impossível de negligenciar ao estado da arte contemporânea na discussão acerca da cognição corporificada.

Palavras-chave: Cognição Corporificada, Filosofia das Ciências Cognitivas, Filosofia da Mente, Enativismo, Representacionismo.

$\mathbf{O}$ ne of the most perennial discussions in philosophy is certainly about who we are, that is, about our nature as human beings. The main tentative answers put the stress on our thinking, cognition and rationality to draw the relevant distinctions between us and other animals. So the question "who we are?" is often conflated with the question on "what is to think?" or "what is to be rational?". With those questions in mind we are trying to explain the singularity of being a human being. Some qualities that may be used to distinguish us from other organisms are often put on the table, as our ability for civilisation and to protect us from the savage world. Or our special understanding of good and evil and how to act morally, because we are often thought of as rational beings in a world of irrationality. Our language may be also held as what separate us from other animals and keep us apart from irrationality. Another alternative is to put the emphasis on our alleged free will as a way to pave our peculiarity. Some bet on our capacity of loving or apprehending the grounds for the true happiness. Others defend that our peculiarity consists in knowing that we will at last die.

A traditional philosophical answer that seems to connect all the qualities above grounds our singularity on an immaterial substance, purely rational that we possess or that constitutes our true being. We have variations of this narrative in several influential authors over the history of philosophy. Other authors instead defend that all those criteria are not necessary nor sufficient to 
determine our humanity and that the very idea of an immaterial and intellectual substance independent of material and worldly offers is far from uncontroversial; in fact, it is a misleading idea.

The traditional answer and its developments mentioned above motivates what Hutto and Myin (2013) call I-cognition, a view based on an amalgama of internalist, intellectual and individualist accounts of our rationality and what should make us special. In contemporary philosophy, this traditional way-out incorporates to the idea of an immaterial, intellectual and individual substance the important notion of manipulation of symbolic representations in the brain. The special cognition that we entertain should be brain-based and display a sophisticated mechanism for manipulating ideas or images about the world. We think because our brain compute. In this view, we should capture, process, model information in order to act in the world. In other words, cognitive processes that give rise to such cognitive activities take the form of brain-based computation over internal and private mental contents. Accordinly, the only kind of cognition relevant for us takes place in the intellectual interior of special animals, conveniently, us.

One of the largest problems with this traditional approach is that if the brain really were a representational deviceone that only had access to its own contents-then it would be in no position to compare in any direct way what it represents as being the case with what really is the case in the world. As a result of this internalist account, we would be special but also radically separated from the nature. We could hardly fill the gap between our subjectivity and the objectivity of the world, and worse, between our internal states (mind) and our body. This internalist way-out is indeed a wide open door both to dogmatism and to skepticism.

Several contemporary philosophers have been developing tenets in pragmatism (broadly construed) to motivate it as an alternative philosophical foundation for a comprehensive understanding of cognition, opposed to this far-reaching representationalist tradition. As we saw, this long-established internalist tradition in philosophy of mind and cognitive scien- 
ce defends that cognition is fundamentally content-involving as it is fundamentally constituted by internal and intellectual manipulations of representations. On the other side, some radical contenders advocate that cognition is neither basically representational nor does it involve, as in usual internalist views, processing or manipulating informational contents. They call attention to the importance of inherited and embodied practices and social interactions in order to understand relevant topics in perception, language and the nature of intentionality. They take seriously evolving biological systems and situated individuals interacting in communities over time as preconditions of our rationality, features often dismissed as not central in the representationalist and internalist tradition.

In the context of this discussion on the nature of mind, thought, cognition and rationality, the last decades indeed witnessed the rise of E-cognition as an alternative to I-cognition. The former is interactive, relational and dynamical and provides original tools for our understanding of what we are. This approach thus incorporates further biological insights into the debate about cognition, by calling attention to basic facts about living organisms such as their perpetual activity of self-construction (autopoiesis), their need to be constantly adapting to the changing conditions of the environment (adaptivity), and their selective responsiveness to specific aspects of the environment creating their own world of significance (enaction). Following on this trend, radically enactivist approaches take the bold further step of proposing the complete removal of representational content in the explanation of cognition in basic minds (as REC, Radical Enactivist), not only for simple organisms but also at human level. Accordingly, the conservative view that content is the mark of the cognitive should be rejected. As a result, neuroscience ought not continue to focus on the development of methods and techniques that enable us to study what causes what in the brain. Philosophy, according to E-cognition, should offer a theoretically sophisticated and parsimonious way of making sense of work on cognition without introducing unnecessary theoretical extravagances and allow 
us to avoid deep theoretical mysteries as the existence of the immaterial and intellectual substance.

Together with embodied, embedded, ecological approaches, this radical research program has been successful in providing explanations for a wide variety of basic cognitive phenomena (Hutto and Myin, 2013). However, a straight solution to the full naturalization of the concept of content and mental representations requires inter alia explaining how it is possible to get from informational foundations that are allegedly non-contentful to a full theory of mental content using only naturalist resources. The question is how to provide a complete and gapless naturalistic account of cognition. Additionally, critics concerning the possibility of a full-fledged enactivist program have been posed, such as the so-called "scale-up objection", namely, the challenge of proving itself relevant for the investigation of traditional problems related to higher level cognition involving concepts such as contentful information, representational states, symbolic thought, logical inferences, mathematical knowledge, etc. As the recent developments witness, the question has not yet been settled and the debates are reaching a critical point.

Hutto and Myin 2017 follow-up book gives an authoritative contribution to this critical point. In 2013, they argued that basic cognition does not involve being in contentful states of mind, where "to be in a contentful state is to take ('represent,' 'claim,' 'say,' 'assert') things to be a certain way such that they might not be so". Against CIC (cognition involving content), RREC (really radical enactive cognition), CEC (conservative enactive cognition), Daniel Hutto and Erik Myin called their theory the "Radical Enactive, Embodied account of Cognition" ("REC").

The 2017 book's principal aim (already announced in its subtitle) is to explain how basic cognition and content-involving cognition combine in human cognition to give a full account of the relation of our inferential and judgmental powers with our alleged contentless basic cognition. In fact, Hutto and Myin in their new work are addressing indirectly a traditional Kan- 
tian problem: how do we pass from perception to belief and judgment? For Kantian-oriented philosophers, perception should be already conceptual to bridge the gap between perception and higher level cognition. The issues concerning application of our concepts to our perception seems to impregnate it with intentional content through and through.

However, according to the REC account already presented in 2013, "basic mind" or "basic cognition" is "contentless." "Basic cognition" means all cognitive activities except those involving public language and cultural symbol systems. From the REC perspective in their new book, content is not a feature of all cognition, rather content-involving cognition is a special achievement of special social animals. Since "content" should mean possessing correctness conditions (accuracy or truth conditions) and since Hutto and Myin deny Kantian and Cartesian answers that incorporate representations throughout our cognition, they have to provide an account of how does content emerge in the nature. For that, they defend what they called a duplex account, namely: the biological and natural basis should meet the social platform in order to content rise in nature. Going radical, the REC-way is to abandon the information processing and representationalist views of cognition in favor of a purely embodied know-how account. If basic minds lack content, then they lack vehicles that bear content. According to this view, intelligent beings capable of contentful thought, like us, should have participated in and mastered established socio-cultural practices - practices involving public representations that depend for their existence on a range of contingent customs and institutions. Participating in such established socio-cultural practices is a necessary scaffold for the emergence of content-involving forms of cognition.

Drawing on 2013, Hutto and Myin aim at paving the way to avoid former common criticism in their 2017 book, namely that they are offering much more a proposal than an account. The recurrent criticism goes on saying that REC is not positive. It makes only destructive remarks against cognitivism. Hutto and Myin should address those issues to turn their pro- 
posal into an account. Even if REC account is positive, it is allegedly too basic. It cannot "scale up", critics say. If they are right in this view, there is still the big question as to how socio-cultural practices evolved from contentless minds.

The new book is divided into two main parts. The first one, which encompasses six chapters, is more critical and aims at clarifying REC's duplex account of cognition while the second part, constituted by three chapters, is more positive since it is concerned with the application of this framework into specific philosophical topics as perception, imagination and memory. In what follows we briefly describe each chapter.

In chapter one, entitled "Revolution in Mind", the authors maintain, in line with their 2013 book, that "limitations are especially conspicuous when it comes to trying to explain the intelligence of fast-paced, spontaneous, but skilled performance in terms of classic reasoning processes involving the manipulation of in-the-head, abstract symbols and propositions" (p. 1). They attack central tenets of cognitivism, which has enjoyed the status of the default approach for cognition in the sciences of mind since the 1950s. The authors show then that propositionalism is the pervasive tendency "among analytic philosophers to understand content in essentially propositional terms" (p.11). It is important to note that liberal use of the notion of content should not mask the fact that a great deal of argument would be needed to establish that all acts of world-engaging experience, perceiving, or thinking involve contents with conditions of corrections. Those persuaded by this criterion would find it simply unthinkable that cognitive science could ever abandon the idea that basic states of mind are representational and content-involving. (p. 14). Hutto and Myin then defend that an analytic defense of unrestricted CIC is not open to anyone who adopts the kind of naturalistic approach to philosophy that cognitive science demands. A problem with this chapter is that it still seems much more a manifesto than an elaborated account. A sign for that is that they provide us with much more negative remarks than positive. 
The second chapter, named "Reasons to REConceive", suggests the ambitious revolutionary character of their enterprise while it shows the need for a crucial revision of the standard picture. They want to remove barriers to make progress possible. REC asks us to REConceive and RECast our understanding of what cognition is, of how it works, and of what it does. "It asks us to fundamentally adjust how we think about minds." (p. 51) The thesis of this chapter may be summed up as follows: the information processing gloss, typical of the mentalist way of seeing our internal life, is superfluous to understand cognition. Irrespective of being grounded in our soul or brain, cognition should not be thought using the computationalist model based on information that is encoded, decoded, processed, transmitted, retained and retrieved. According to the familiar cognitivist account, information is supposed to be picked up via the senses through multiple channels, encoded, and then further processed and integrated in various ways, allowing for its later retrieval. Instead of that, Hutto and Myin do what they already have done in 2013, they approach cognition in Wittgensteinian terms, that is, by using know-how performances, competences and abilities. They also apply Wittgenstein's method to philosophy, when they state that "certain conceptual problems do not warrant straight solutions, they warrant dissolution by rethinking the underlying assumptions that bring them into being and make them seem, at once, intractable yet unavoidable (p. 39). Against the view that sees normativity in the natural world they also spell out a negative verdict on the shortcomings of teleosemantic accounts. They advocate that in this account there is a root mismatch between representational error and failure of biological function. Voicing several influential authors they hold that we are warned that "evolution won't give you more intentionality than you pack into it" (Putnam 1992, 33); that there is a crucial distinction between "functioning properly (under the proper conditions) as an information carrier and getting things right (objective correctness or truth)" (Haugeland 1998, 309); that "natural selection does not care about truth; it cares about reproductive success" (Stich 1990, 62). And, for example, as Burge $(2010,303)$ reminds us : "Evo- 
lution does not care about veridicality. It does not select for veridicality per se."

The third chapter "from Revolution to Evolution" aims to achieve conceptual evolution by RECtifying and radicalizing existing enactive approaches to cognition through a process of philosophical clarification. REC should, for example, propose adjustments to Clark's own attempt to unify theories of cognition through the lens of his PPC (Predictive Processing account of Cognition). Both accounts have similarities because they conceive mind in action-oriented terms and hold a dramatic reversal of the classical-sense-model-act, as both approaches treat basic cognition as fundamentally active, world-involving, and self-organizing. Hutto and Myin state that "the REC take on PPC is that although we have ample reason to think that brains play a central role in enabling embodied expectations, we have exactly no grounds to suppose that the brain does its important work by modelling or describing anything at all". (p.74) According to PPC, brains do not sit back and receive information from the world, form truth evaluable representations of it, and only then work out and implement action plans. Instead, tirelessly and proactively, our brains are forever trying to look ahead to ensure we have an adequate practical grip on the world in the here and now. (p.58). Their criticism against Clark's PPC is that its end result is an intellectualized enactivism. The key point is that Clark tells the story of matches and mismatches in contentful terms. And that is the sin of his enactivist proposal. Accordingly, a RECtification allows PPC to avoid intractable theoretical problems and results in a stronger, more positive, and potentially unifying view of basic cognition and the brain's role in enabling it. (p.64) Against the intellectualist view Hutto and Myin state: "to fully understand the nature of the problem, it is important to recognize that cognitivist takes on PPC are strongly committed to the assumption that brains and scientists are engaged in essentially the same kind of intellectual work." (p. 64). It is however noteworthy that this line of discussion makes the classical model implausible but not impossible. Hutto and Myin do not give us an account in which we have criteria to distinguish a physical system that manipulate 
content from another one that does not. In other words, while we examining a physical system when can we say that it is contentful or not? In this chapter there is really no advance in comparison to the former book concerning this topic.

The fourth chapter on "RECtifying and RECconecting" shows how to re-conceptualize things to get other enactivists straight, as autopoetic enactivists, Clark's enactivism again, Chemero's proposals and ecological psychology accounts. The point here is to reconfigure prominent accounts - for example, Autopoietic-Adaptive Enactivism and Ecological Psychology , in order to show that these approaches are better and stronger when partnered with REC, rather than with some variant of cognitivsm when it comes to examine the nature of basic minds. Crucially, the idea that any information is actually collected from the world - that any information somehow "gets inside" the perceiver's head and is neurally processed - is an in-between position that is very un-Gibsonian, they hold (p. 83). The 2017 thesis is that content is only available to certain enculturated beings but that does not mean an engagement in anthropocentrism and anthropomorphism in cognition. However, we, readers, remain with the following questions: content is not necessary for the existence of culture? How can we have linguistic communities without contentful exchange between their inhabitants? The more we think about it the more it seems that content is the condition for culture and not its result.

The fifth chapter entitled "UR-Intentionality: What is it all about?" is meant to show that representationalism is not inevitable when dealing with intentionality. REC seeks to leave behind the claim that basic minds are contentful, while nonetheless holding on to the claim that they exhibit a kind of basic intentionality. (p. 94) Hutto and Myin defend that we should let go of the idea of a sense-reference to understand the directness to some relevant targets in our environment. The puzzle here is an alleged incongruence between lack of content and intentionality or that intentionality and content are mutually necessary. Our authors defend that this shows a tendency to make intentionality intelectual and propositional. They defend 
we should abandon the idea that the most basic forms of intentionality must be contentful or representational in the sense of having sense, reference, or correctness conditions. For that they introduce the following important distinction concerning the concept of intentionality: being about something, in respect to something, in contrast to to be directed towards or to have something as a target. This means a distinction between aboutness and directness. Although they are very often treated as if they are equivalent, they are not. The consequence of the hyperintelectutalism concerning intentionality is to leave unspoken the kind of directness that we have in basic cognition and in non human animals. This chapter displays an example of a great philosophical work on the revision of the contemporary relevant literature and on criticism of Searle's so-called top-down strategy. They propose the inverse strategy, to hold a bottom-up explanation of intentionality and then investigate how things scale up. The positive part on the debates between teleosemantics and teleosemiotics seems to be already in the chapter V from the 2013 book. Further, Hutto and Myin maintain that the phenomenological concept of nonrepresentational intentional content means "simply whatever object a given intentional attitude targets or is directed at" (p. 102). However, intentional content also includes how the object is presented to the targeting attitude. Specifying intentional content requires characterizing not just the object itself, but also how the object appears to the agent, including the significance and relevance it has for the agent, given the agent's bodily and cognitive skills, and affective and motivational tendencies.

The sixth chapter "Continuity: Kinks not Breaks" ends the first and longest part of the book. They deal with what we called the Kantian puzzle concerning the connection between perception and judgement by using social and normative notions. As we saw, the Kantian problem can be stated as follows: how do we pass from perception to belief and judgment? It seems that perception should be conceptual because our judgments apply systematically to it. Against this view, Hutto and Myin hold that "it is possible, in principle, to explain the origins of content-involving cognition in a scientifically respectable, 
gapless way. RECers aim to do so by making special reference to the important role played by sociocultural scaffolding." (p. 122). The job is then to seek to explain how contentful states of mind actually come into being through a process of mastering special kinds of sociocultural practices. REC holds that the development of such intersubjective practices and sensitivity to the relevant norms comes with the mastery of the use of public symbol systems. Hutto and Myin maintain: "Content only arises when special sorts of sociocultural norms are in place. The norms in question depend on the development, maintenance, and stabilisation of practices involving the use of public symbol systems through which the biologically inherited cognitive capacities can be scaffolded in particular ways." (p. 145) In this context, their distinction in the image of evolution between launchpad and a leash is insightful, as we can think of evolution as putting in place platforms that act as launchpads, not leashes. Beyond this, our authors defend, for the sociocultural emergence of content, we need to assume that our ancestors were capable of social processes of learning from other members of the species, and that they established cultural practices and institutions over time. Although this chapter displays a discussion about anthropology in a relaxed naturalism, far from enough studies were indeed presented and discussed. Concerning socio-cultural scaffolding we should ask how contemporary tenets of social ontology could be helpful, as shared intentionality, collective attention, mutual recognition. For there is an important sense in which directness should be collective to get the kind of intentionality we need in order to understand the content of our propositions. A better understanding of what they mean by content should be given here too. Sometimes REC reads as though Fodor was right about what content is, and we just need to supplement a Fodorian account of content with an enactivist account of contentless world-tracking dynamics. But at other times the emphasis is put on the role of scaffolding socio-cultural practices. That would seem to align their project much more with a neo-pragmatist account of content, such as a Brandomian one. An account of content in terms of inferential states instituted by normative statuses seems 
far more compatible with enactivism than a strictly cognitivist account. However, the role that inferences play in this context and the so-called game of giving and asking for reasons are unfortunately not even mentioned in this chapter. We worry that the duplex account view, pushes contentless cognition and contentful cognition so far apart that it becomes a mystery as to how they are functionally integrated. As for a Cartesian author is hard to explain how mind and body interact, for RECers is difficult to explain how contentless cognition connect to contentful cognition.

The second part of the book is meant to be more positive. Its first chapter "Perceiving" adopts a throughout nonrepresentationalism about perceiving when it comes to understanding both its processes and products. It is defended that "there is an important difference between something's looking or feeling a certain way and its being taken to be a certain way" (p. 149). Hutto and Myin are against what they call analytic strategy connecting perception and content, that is, the idea that perception might be contentless is "manifestly implausible." Simply put, in this analytic approach, if someone perceives, someone represents it, necessarily. However, it is pointed out that our philosophical intuitions about cases might be wrong. It is wrong to scale up from one "obvious" case. Hutto and Myin hold, for example, that "the evolution of debates around this very topic provides a salutary lesson of the dangers of making unshakeable a priori pronouncements about what essential properties perceiving must have based solely on what our intuitions tell us has to be the case." (p. 149) In fact, there is no strict contradiction in the idea of perception without content, if we, for instance, examine the responsiveness in nature and how animals are responding to objects. As a consequence of that in debates about whether the future of cognitive science lies with representational or nonrepresentational approaches to cognition, the method should be: "(...) to stay firmly focused on what the explanation of phenomena requires." (p. 150). The point is to be consistent with REC and motivate its way also concerning perception in order to let go the model Capture-model-act concerning perception. Perceiving does not need to en- 
tail content, correctness conditions, truth, accuracy, veridicality and fulfillment conditions. However, it is far from easy to explain how basic perceiving meets content. How can purely contentless perceiving systematically give rise to and interface with content-involving perceptual judgments? And how can contentful perceptual judgments influence basic perceiving and how does such perceiving unfold? In general, the question is: How can contentless and contentful forms of perceiving enter into systematic commerce with one another if not-per impossible, according to REC-through some kind of contentful communication? The thesis that the authors pursue is that the patterns that matter for the interactions that matter is the crucial point. "The suppressed assumption is that cognitive integration and interaction at every level must always take a communicative form. REC's answer is straightforward: the interface between perception and thought can be understood in basically the same way as intermodal interaction: with reference to an organism's interactional history. Interaction and history explain what, why, and how we perceive". (p. 172).

The second chapter of the second part concerns "Imaging". In general, we use imagination in philosophy to deal with different particulars and generality, to represent counterfactual scenarios, and to talk about the past, present, or future by doing approximation, anticipation, guessing and surrogation. In this context, the addressed question is "when and where do representational contents actually play a substantial role in accounting for how imaginings do their important cognitive work of enabling creative feats of planning; practicing and executing perceptual-motor tasks; producing works of art; developing novel technologies; and so on?" (p. 183) The objective of this chapter is to tell a story about mental imagery and basic forms of imagining in REC terms, thus providing an explanatorily adequate account of basic imagining without content. REC opposes unrestricted-CIC accounts of the imagination that assume all imaginings, even the most basic ones, always possess contents with some kind of correctness condition, whether that such correctness conditions are understood in truth-conditional or semantically less demanding terms. To complete REC's 
account of basic imaginings, what is needed are details of the kind of work basic sensory imaginings, those that entirely lack representational content, might do and how it might be done. "Thus even if we allow", Hutto and Myin say, "that mental models in some sense of that notion are important for understanding basic imaginings, there seems no compelling reason to suppose that assuming such models have representational contents and correctness conditions will help us to understand how basic sensory imaginings execute their important cognitive offices." (p. 201) Their main argument shows that "certain correspondences holding between the model, the modelled, and the imaginer's systematically engaging with the model appropriately because such correspondences hold. What does not seem to be required, and no argument has been supplied to suggest otherwise, is that imaginers or their subparts need to "take" such correspondences to hold, or that any conceptual or symbolic attributions are made to that effect." (p. 200)

The final chapter entitled "Remembering" investigates the difficulty in finding, say, an essence underneath all kinds of remembering-episodes. Concerning memory, Hutto and Myin note that "at one end of the spectrum we find kinds of remembering that are purely embodied and enactive. At the other end we find content-laden forms of memory. In between, we find forms of pure episodic remembering that appear to require simulative imagination" (p. 203) The point of this chapter is to adopt duplex account to different remembering-episodes. In this context, it is important to show that the thesis that basic function of remembering is primarily to extend our representational capacities beyond perception is not nuanced enough and in some cases may be misleading. Memory is usually thought of as a device to store, retain, and then to reproduce information about the world. In this view, memory is fundamentally about representational fidelity. Hutto and Myin note that "memory, so the picture tells us, extends our cognitive contact with the world beyond the here and now of perception. This is achieved, according to a modern variant of this story, by retaining and manipulating information that when recovered and recombined in the right ways enables individuals to reproduce their contentful 
takes on past happenings." (p. 222). However, we are left with the following perplexity: if our memory is very often unsuccessful and unfaithful, why its primary function should be to give us accurate representations about our past? Memory has at least the following problems concerning its lack of accuracy: the change of perspectives of who experiments and who is observed, distortions about the sequence of episodes, distortions about the limits of what was in fact perceived, false memories about true facts, implanted memories about our infancy, imagination inflation and complicity of partners in memory mistakes. This chapter exposes the theoretical difficulties that the content-based view encounters in trying to maintain that the primary function of remembering is faithful reproduction of past content in light of the fact that it everywhere so spectacularly and reliably fails at that task. (p. 223) Accordingly, Hutto and Myin bring to the discussion the social immersion and support and the affective dimensions and social benefits of autobiographical. They emphasise the role that social cohesion, regulation of expectations, plans for future, direct actions, forging and maintaining "intimate and longstanding relationships play in our memory, as seeking the truth about our past is a sophisticated business, one we are only able to conduct at all because of our familiarity with the norms of this peculiar social enterprise." (p. 231).

The thesis of this chapter is that only individuals who acquire the ability to fashion autobiographical narratives about their past could have any properly meaningful contentful thoughts about their memories. Accordingly, nondeclarative remembering differs fundamentally from acts of remembering that could feature in autobiographical narratives in that the former does not inherently involve any kind of contentful representation of particular happenings. Embodied or enactive forms of remembering, as exemplified by procedural memory, do "not store representations of external states of the world" (p. 206). As a result, the mastery of narrative practices makes possible a wholly new and unprecedented kind of memory, as autobiographical remembering depends on scaffolded social interactions. For it might be argued that it is only through the process of 
mastering linguistically mediated practices that one encounters the kind of cognitive friction needed to learn how to make contentful claims, and thus for getting things right or wrong.

Their 2017 book's Epilogue deals with neuroscience, neurodynamics and the role of brain. The view that what is outside the head may not necessarily be outside the mind is defended. The topics of "representation", "internality" and "intellectual manipulation" is again addressed in the context of the theoretical disagreement between REC and CIC. Hutto and Myin address critically the traditional notion of information in this chapter as it is "something that they assume is acquired, processed, pooled, mapped and remapped, and generally made use of by the brain" (p. 233) According to REC, information should not be thought as processed and represented by the brain. The assumption that rule-based information is stored does no additional explanatory work. Neural activations are not actually "coding," "computing," "conveying," or "communicating" information. Information is not really picked up, or passed on, or pooled in the brain. The problem is put as follows: "Why assume stored information or contents play any part in simulatively reenacting an experience if stored information and contents are not needed for procedural memory? (p. 235)

In all those chapters it seems, as in their 2013 book, that no real developed account is given but only a (persuasive) defense of the viability of such an account to come. Although Hutto and Myin do a very good job in highlighting the problems with the concept of representational content used as an explanatory tool in cognitive science, they provide no full-fledged alternative theory of intentionality, only hint of a social oriented way-out. Hutto and Myin actually do not provide a detailed explanatory model of how social cognition and public symbols systems give rise to contents in connection with basic cognition. They do not explain, for instance, how social cognition and public symbol systems can come into being without the prior existence of mental contents. Moreover, how perception can be false if it has no content? We act upon false perception; we make decisions grounded in false representations of what is 
going on in our perception. The connections to inferentialism, social ontology, shared intentionality, mutual recognition and (neo-)pragmatism should be developed to redeem REC from these pieces of criticism. Although rejecting critics and rival theories with philosophical arguments does not do the work of providing a detailed cognitive science theory, one may say that Hutto and Myin 2017 originally address the perennial philosophical issue about our nature as human beings giving an impossible-to-neglect enactivist contribution to the current state-of-art in the discussion.

\section{Literature:}

BURGE, T. The Origins of Objectivity. Oxford: Oxford University Press, 2010.

CLARK, A. Surfing Uncertainty: Prediction, Action and the Embodied Mind. Oxford: Oxford University Press, 2016.

HUTTO, D. D., and MYIN, E. Radicalizing Enactivism: Basic Minds without Content. Cambridge: MIT Press, 2013.

PUTNAM, H. Renewing Philosophy. Harvard: Harvard University Press, 1992.

HAUGELAND, J. Truth and rule-following. In Having Thought: Essays in the Metaphysics of Mind, ed. J. Haugeland. Harvard: Harvard University Press, 1998.

STICH, S. The Fragmentation of Reason: Preface to a Pragmatic Theory of Cognitive Evaluation. Cambridge: MIT Press, 1990. 


\section{Traduções}


